\title{
Improving the Performance of Vertical Wind Turbine Using Gears and Timing Belt Mechanism to Reorient the Turbine's Blades
}

\author{
Khaled M. Khader \\ Production Engineering and Mechanical Design Department, Faculty of Engineering \\ Menoufia University, Shebin El-kom, Menoufia, Egypt \\ (Corresponding author: khkhm62@hotmail.com)
}

\begin{abstract}
Vertical Axis Wind Turbines (VAWTs) are steadily continued to gain more attention from both academia and governments as they can provide promising solutions for harnessing wind energy in locations with modest wind speeds as well as varying wind directions. In spite of all of the flexibility in working conditions as well as low installation costs and ease of maintenance associated with the VAWTs, their lower efficiency levels significantly obstruct their competiveness in the wind energy field. Therefore, enhancing the performance of such turbines is very critical in exploiting their full potential. Accordingly, this paper proposed a mechanical mechanism which is mainly consists of gears and timing belt that are specially designed to effectively enable the turbine blades to instantaneously reorient themselves to face the wind direction. Also, the proposed turbine is enclosed in a specially designed cage with a rear blade attached to it. This rear blade, as affected by the wind, is responsible for making the cage redirect itself such that its inlet is facing the wind direction. To test the validity of the introduced concept, a VAWT prototype with the proposed mechanism has been manufactured and tested using wind tunnel. The test results demonstrated the self-oriented capability of new design that guaranteed maintaining a continuous perpendicular position between the affecting wind direction and the blade surface. The experimental results also confirmed the expected efficiency improvements and the assessed natural theoretically frequencies ensured that the developed turbine can safely rotate with considerably high angular speeds with no resonance risks.
\end{abstract}

Keywords: Gears and Timing Belt Mechanism; Self-Oriented Blade; Vertical Axis Wind Turbine (VAWT); Finite Element.

\section{Introduction}

The contemporary civilization can be essentially attributed to the availability of energy resources as one of the critical enablers of development in different life sectors. With the currently increased awareness of environmental issues accompanied with the unsustainability of conventional energy resources, there is an inclusive consensus on the importance of renewable energy sources in coping with the increased energy demand while managing ecological and economical challenges [1, 2]. Particularly, the world is threatened by an expected global climate crisis that has to be rationally managed. Since the energy sector is one of the major contributors to the pollution and the global warming, the deployment of renewable and clean energy should be widely considered to help in protecting the environment and mitigating the effects of the accelerated climate changes [3]. According to the British Petroleum (BP) statistical review of world energy (2020) [4], an ongoing encouraging growth of renewable energy has been declared. Specifically, it has been reported that renewable sources have their largest increase in energy terms on record (3.2 EJ) during 2019. Besides, renewable sources enhanced its share in the energy mix from $4.5 \%$ in 2018 to $5 \%$ in 2019 [4]. Despite the reported growth, the contribution of renewable sources in the energy mix is still relatively small. Therefore, more governmental and academic efforts should be focused to help in exploiting renewable energy sources more effectively. Generally, there are some research publications that addressed the opportunities of renewable energy transition and highlighted on technology improvement and innovations to facilitate accelerated transitions [5]. However, others focused on developing models for selecting the most appropriate systems or sources of generating renewable energy in particular locations based on multiple criteria [6-11]. Reviewing the recent reported growth with respect to 
renewable energy source, the BP statistical review of world energy affirmed that wind generation has provided the largest share in the reported growth (1.4 EJ), followed closely by solar energy (1.2 EJ). However, with respect to the countries contributed to that growth, China was the largest contributor to renewable energy growth $(0.8 \mathrm{EJ})$, followed by the US (0.3 EJ) and Japan (0.2 EJ) [4]. Typically, Egypt is one of the countries with substantial opportunities in renewable energy generation [12-16]. Despite the conspicuous growth rate in renewable energy generation (in terawatt-hours TWh) that has been reported in Egypt from (3.5 TWh) in 2018 to (6.5 TWh) in 2019, oil and gas are still its main energy sources. This recorded growth in Egypt is mainly attributed to solar energy firstly, followed by wind energy [4].

All over the world wind energy has been categorized as a promising clean and renewable source of energy; particularly in Egypt as it has encouraging opportunities due to the natural aspects as well as the governmental interest [17]. Generally, wind turbines are mainly used for converting the kinetic energy of moving air into a rotating mechanical energy to be converted into electrical one via generators [18]. Wind turbines can be basically classified, with respect to the configuration and orientation of their axis of rotation, into Horizontal Axis Wind Turbines (HAWTs), and Vertical Axis Wind Turbines (VAWTs) [19]. Several studies have focused on comparing these two types of turbines as well as highlighting the advantages and limitations of each type [20-22]. Essentially, higher energy efficiencies can be achieved using HAWTs and hence reducing the cost of power generated, but this can be realized only with high wind speeds. Further, high wind turbulence, variations, or excessive directional variability can result in substantial problems in using HAWT. On the other hand, VAWT have demonstrated an ability to fulfill certain energy generation requirements that cannot be generally fulfilled by HAWTs [22].

Despite the lower efficiency as well as the varying output associated with the VAWTs, researchers highlighted various advantages of the VAWTs that might outweigh their limitations particularly in some circumstances. Specifically, VAWTs are almost capable to harness the wind from all directions so that it can function with any wind direction. Besides, these turbines do not necessitate high wind speeds to produce power. Hence, these can be installed in locations with modest wind speeds and can be also installed close to the ground level which results in easier maintenance and control. In addition, because they generate lower forces on their support structure, they have simpler structural design and they also result in lower levels of noise [21]. Further, VAWTs can provide promising solution for power generation in distinct locations far from the integrated grid systems [23].

Basically, there are various VAWTs design variations according to the working principles as well as the blade shapes and their configurations. A comprehensive review of these different types and their performance has been introduced in [23, 24]. Generally, the VAWTs can be classified into two main categories. The first one is the Savonius type which is a drag-driven turbine, while the other is the Darrieus which is a lift-driven turbine [20]. Despite the simplicity and higher starting torque of the dragbased turbines as opposed to the lift-based ones, the drag-based are characterized by lower efficiency levels $[25,26]$. Accordingly, researchers have investigated the design of a combined SavoniusDarrieus turbine for exploiting the advantages of both types [27-30].

Performance assessment and improvement of VAWTs have been extensively addressed by several researchers during the last two decades. The performance of different designs and configurations of the VAWTs as well as the effect of different design parameters have been investigated using different approaches. For instance, VAWTs have been experimentally tested using wind tunnels [3133]. Besides, Computational Fluid Dynamics (CFD) simulations have been effectively employed in investigating the mechanical performance of the VAWTs [25, 32, and 34]. Other researchers have utilized field experiments to study the effect of wind characteristics such as wind speed, wind direction and turbulence intensity $[35,36]$. While, with considering VAWT performance improvement, different design modifications and optimization as well as innovative design ideas have been introduced in the literature. Typically, the effect of blade shape parameters on the self-starting capability and power extraction efficiency has gained the focus of researchers [37-40]. However, others have focused on enhancing the performance through using composite blades [41, 42]. Further, the effect of the number of blades utilized in particular VAWTs has been also investigated [36, 43]. Besides, some researchers had focused on using different configurations of the turbine blades such as cross axis turbine proposed in $[31,44]$. While, others have promoted boosting the turbine using different wind guiding devices for enhancing the performance such as guide vans, wind shields, and deflectors. A comprehensive review of such devices and their effect on the self-starting capability as well as the generated power was provided in [45]. 
It is evident that VAWTs airflow controlling attachments can significantly improve its performance. Basically, the ultimate performance of the VAWTs can be attained as long as the active wind direction is perpendicular to its blade surface. Even with wind boosters, this perpendicular position cannot be continuously maintained during a complete cycle. Definitely, as soon as the wind starts to rotate the turbine blade, the angle between the wind direction and the blade surface will start to deviate from the perpendicular position. Specifically, this angle may vary from $0^{\circ}$ to $180^{\circ}$ along the turbine's complete rotation. Accordingly, the ultimate objective in designing a VAWT is being capable of perpetually maintaining the perpendicularity between the affecting wind direction and the blade surface. However, reviewing the literature unveils that most of the research publications concerned with VAWTs performance improvement are mainly focused on either using different blade shapes, materials, configurations or employing wind guiding devices. Generally, there is a distinct lack of research considering instantaneously redirecting the blades to promptly face the wind direction. On the other hand, a few of research presented novel ideas for continually reorienting the blades to face the wind direction as in [46], rather than focusing on using wind guiding devices or other design parameters commonly addressed. Accordingly, this paper is concerned with introducing a new concept for the VAWTs; in which the main objective is continuously redirecting the turbine blades to completely face the air during the whole cycle of rotation. The proposed VAWT design is mainly composed of four flat selforiented blades for harnessing the most of wind energy potential more efficiently. These blades are capable of reorienting themselves through an innovative mechanical mechanism that is attached to the turbine. This mechanism mainly relies on gears and timing belt mechanism that is specially designed to guarantee that the blade surface and the affecting wind direction are perpendicular all the time during the turbine rotation. The VAWT proposed design presented in this paper is theoretically justified and supported by equations for calculating the power coefficient. Besides, a prototype of this introduced designed has been built and tested using wind tunnel for validating the concept and for experimentally assessing the power coefficient, as well. Finally, in order to ensure that hazardous resonance conditions are avoided, the developed prototype is utilized for assessing the theoretical natural frequencies of the proposed design.

\section{Theoretical Basis of the Proposed VAWT Design}

A novel idea has been presented in [46] for enhancing the VAWT design which necessitates using self-oriented flat blades for improving the efficiency of the VAWT. Khader and Nada in [46] proofed analytically that, the introduced novel design has $57 \%$ increasing rate of VAWT power coefficient compared with the usage of the traditional VAWT that has the same number of Savonius blades. Mainly, this novel design relies on employing a Crank-Crank mechanism that is effectively capable of providing a self-oriented ability for the turbine's flat blades. This self-oriented motion guarantees a continually perpendicular orientation between the blade surface and the direction of the affecting wind. Besides, this novel design depends on utilizing a selforiented cylindrical rotary cage to enclose the turbine. This cage has an inlet for airflow in order to diminish the negative drag on the turbine blades. Also, the cage rotates by self-motion through its rear blade for orienting its inlet towards the affecting wind direction without using an auxiliary motor.

This paper presents another new idea for improving the VAWT design, which requires using self-oriented flat blades for enhancing the VAWT efficiency. Mainly, this novel design depends on using gears and timing belt mechanism that is efficiently capable of affording a self-oriented motion for the turbine's flat blades. This self-oriented motion assures a continuously perpendicular orientation between the blade surface and the affecting wind direction. Also, this design relies on using a self-oriented cylindrical rotary cage (barrel) to enclose the turbine as shown in Fig. 1. Half of this barrel has been removed for creating an airflow inlet to diminish the negative drag on the turbine blades. Furthermore, this cage is provided with a rear blade which can give a selfmotion depending on the affecting wind direction for orienting the cage inlet towards the wind direction.

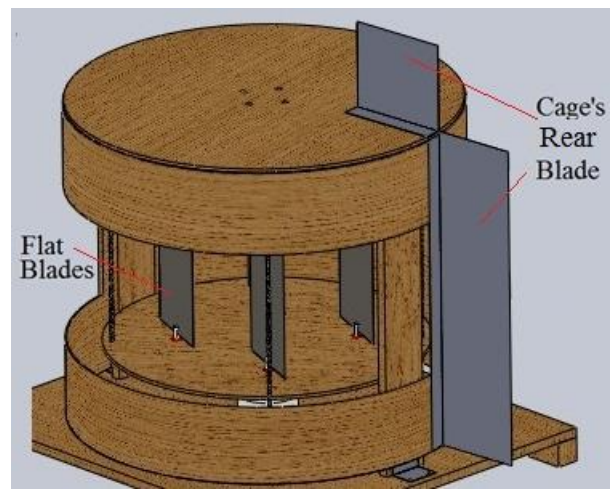

Figure 1- The Proposed Design of VAWT Using Flat Blades 
The idea of this new suggested design consists of two parts. The first part is depending on the cage's rear blade for adjusting the cage inlet towards the affecting wind direction in addition to instantaneously reorienting the turbine's flat blades for orthogonally facing the affecting wind as shown in Fig. 2. The rear blade has been fixed with the cage to continuously redirect the cage inlet to be facing the wind stream. The redirection of the cage inlet can be attained when the wind stream hits the side of the cage's rear blade meanwhile the affecting wind force rotates the cage till the wind stream can go freely beside the cage's rear blade. On the other hand, the orientation motion of the turbine's flat blades for orthogonally facing the affecting wind depends on the connecting rod in addition to the arrangement of the timing belt which engaged with gears (timing belt's pulleys) as shown in Fig. 2. The connecting rod is fixed between the middle gear and the cage. The connecting rod is mounted with the cage, where the connecting rod is collinear with the direction of the cage' rear blade. Also, the flat blades rotating axes are fixed with a suitable timing belt's pulleys which are engaged with the timing belt. These flat blades are assembled to be perpendicular to the connecting rod and the cage's rear blade. When the cage rotates towards the affecting wind by the cage's rear blade with a rotation angle $(\beta)$, the connecting rod can rotate the middle gear with the same rotation angle $(\beta)$. Hence, the middle gears can move the timing belt which can also rotate the outer two gears (timing belt's pulleys) with the same rotation angle $(\beta)$ where the middle and two outer timing belt's pulleys have the same diameters. Thus, the flat blades can rotate around their axes with the same rotation angle $(\beta)$ to keep the orthogonal orientation with cage's rear blade and at the same time to keep the orthogonal orientation with the affecting wind direction as shown in Fig. 2.

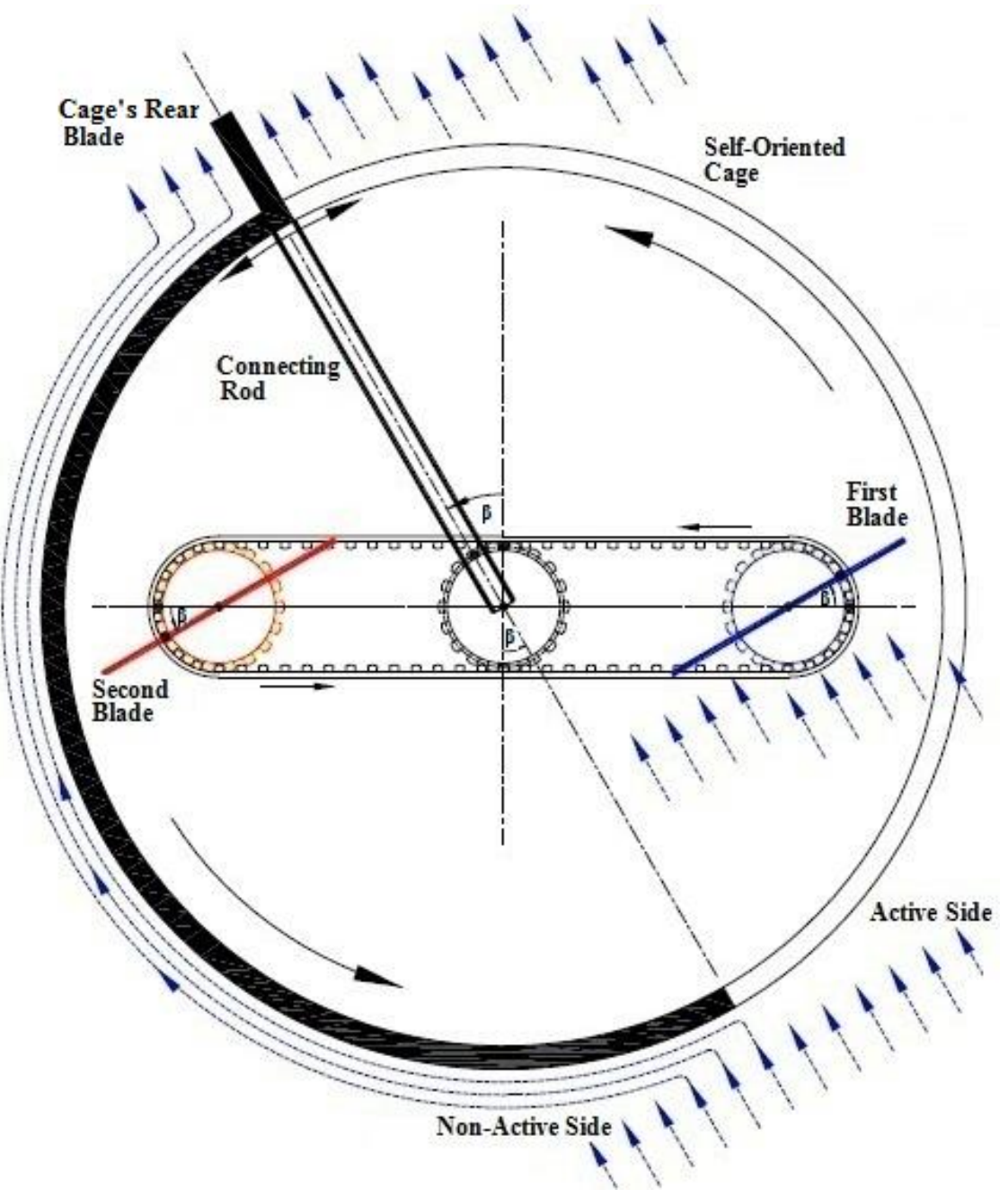

Figure 2- The Adjusting Motion of the Cage Inlet towards the Affecting Wind Direction 

The second part of the suggested design's idea deals with generating the self-orientation ability for the flat blades of the turbine. This orientation ability can always redirect the turbine blades to fully face the air through the whole cycle of rotation. To do so, the connecting rod can keep the middle gear in an immobile situation after attaining the adjusted position of the cage inlet towards the wind direction. Hence, the contact between the timing belt and the stationary middle gear can cause a rotation motion for the two outer gears with a same value of the turbine rotation angle as shown in Fig. 3. This figure indicates two successive orientation positions of the timing belt and the engaged gears related to the turbine's rotation angle $(\theta)$. The centers of the two outer gears are $\left(O_{a 0}\right.$ and $\left.O_{b 0}\right)$ at the first position and these centers become $\left(O_{a l}\right.$ and $\left.O_{b 1}\right)$ at the second position. Also, the initial contact point between the timing belt and the middle gear is $\left(C_{0}\right)$, while the other contact point between the timing belt and the middle gear is $\left(C_{l}\right)$ at the second position.
Similarly, two points $\left(a_{0}\right)$ and $\left(a_{l}\right)$ are denoting two corresponding adjacent contact points between the timing belt and the first outer gears, respectively; while $\left(b_{0}\right)$ and $\left(b_{1}\right)$ are the similar points which are owing to the second outer gear. The contact situation between the timing belt and the stationary middle gear can cause a rotating motion for the outer gears' axes. This rotation motion has the same value of rotation angle $(\theta)$ of the turbine because of the length of the $\operatorname{arc}\left(C_{0} C_{l}\right)$ is equal to the length of the arc $\left(a_{0}\right.$ $\left.a_{1}\right)$ and is also equal to the length of the $\operatorname{arc}\left(b_{0} b_{1}\right)$, where the diameters of the three gears (timing belt's pulleys) are equal.

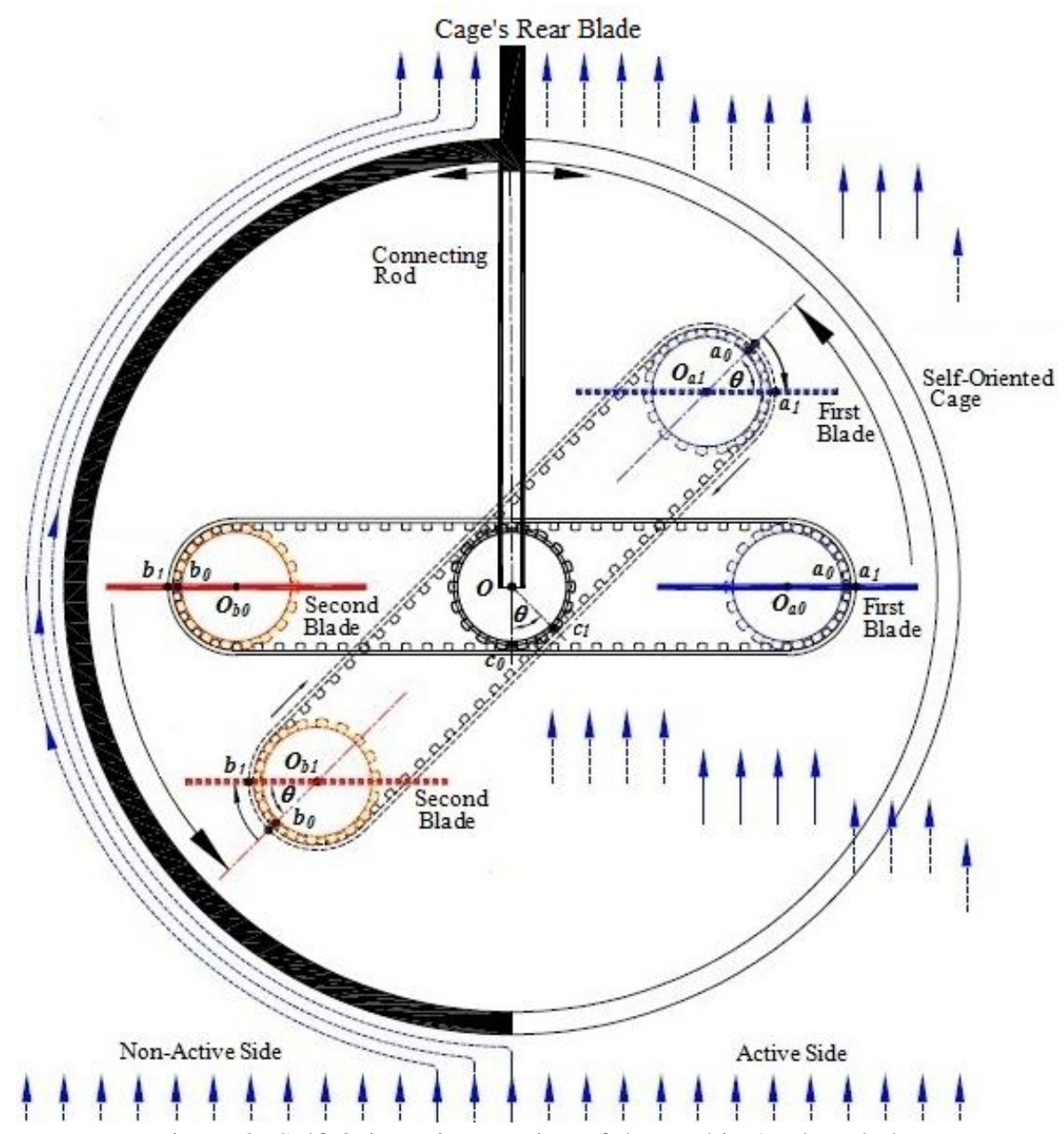

Figure 3- Self-Orientation Motion of the Turbine's Flat Blades 


\section{Detailed Mechanical Design of the Self-Oriented Blades}

The proposed design for enhancing the VAWT performance depends on the usage of four flat blades in addition to an arrangement of timing belts and gears (timing belts' pulleys) beside a suitable rotary cage. This design has an ability to redirect the four blades orientation towards the affecting wind direction during the whole rotation time of the turbine. This directed motion can assure the orthogonality position between the affecting wind direction and the blades' surface for improving the VAWT performance. Two units of timing belt and its gears which are shown in Fig. 4 can be used to guarantee the required self-oriented motion. The four flat blades' surfaces are assembled parallel to each other, as well as the cage must be assembled over its support under an important condition which is the cage's rear blade is perpendicular to the blades' surfaces. Hence, this assembly arrangement assures the required cage self-oriented motion for adjusting the cage inlet towards the air direction and at the same the blades can be oriented to face the wind direction with the needed orthogonal position. Two units of timing belt and its gears (timing belts' pulleys) have been used in this suggested design. These two units are assembled under an important condition which is the two timing belts are perpendicular to each other. Also, the two units are assembled in two different levels for avoiding the interference between the timing belts as shown in Fig. 4. Each unit of timing belt and its gears consist of a timing belt and two outer gears (timing belts' pulleys) in addition to a middle gear. A common middle gear is used for the both two units of the timing belt and its gears. This common middle gear which is fixed with the cage (via connecting rod) can rotate to adjust the flat blade surface towards the cage inlet and the affecting wind direction. After adjusting the cage inlet towards the wind direction, the common middle gear becomes immobile gear for giving the blades the required orientation motion during the rotation motion of the turbine as discussed in the previous section of this paper.

\section{The System Modeling of the VAWT Proposed Design}

The maximum power $\left(P_{\max }\right)$ which can be transmitted from the wind stream to the turbine is;

$$
P_{\max }=0.5 \rho A_{s} V^{3}
$$

Where: $(\rho)$ denotes to the air density which equal to $(1.225 \mathrm{Kg} / \mathrm{m} 3),(V)$ is the affecting wind speed and $\left(A_{s}\right)$ is the total swept area of the turbine's rotor which is exposed to the affecting wind stream. This area is a function in the turbine blade area in addition to the radius of rotation of the blades axes around the turbine axis. This radius of rotation $(r)$ can be also defined as the turbine rotor arm. The turbine blade area is the multiplication of the width $(W)$ of its blade with the length $(L)$ of the blade.

Mostly, the overlap ratio of the turbine blades is the main effective factor for evaluating the swept area $\left(A_{s}\right)$ of the VAWT as discussed by Jian et al., [47]. The swept area $\left(A_{s}\right)$ depends upon the ratio $(\alpha)$, which equal to the blade width $(W)$ divided by the radius $(r)$. This ratio can be selected within the range $(1 \leq \alpha<\sqrt{2})$ for avoiding the interference between the rotating blades as recommended in [46]. The swept area $\left(A_{s}\right)$ can be formulated as follows;

$A_{s}=\left(1+\frac{2}{\alpha}\right) W L$

The theoretical turbine's power coefficient $\left(C_{P}\right)$ at $(\alpha=1)$ of VAWT which has four flat blades can be formulated as in [46], as follows;

$$
C_{p}=\frac{1}{3}\left(\frac{1}{\pi} \sum_{j=1}^{6} C_{p j}\right)
$$

Where: values of $\left(C_{P j}, j=1,2, . ., 6\right)$ can be expressed as follows;

$$
\begin{aligned}
C_{p 1} & =\theta_{1}-2\left(\cos \theta_{1}-1\right) \\
C_{p 2} & =2\left(\theta_{2}-\theta_{1}\right) \\
C_{p 3} & =-1.5\left(\cos \theta_{3}-\cos \theta_{2}\right)+1.5\left(\sin \theta_{3}-\sin \theta_{2}\right) \\
C_{p 4}= & 2\left(\cos \theta_{4}-\cos \theta_{3}\right)-2\left(\sin \theta_{4}-\sin \theta_{3}\right) \\
C_{p 5}= & -2\left(\cos \theta_{5}-\cos \theta_{4}\right)-2\left(\sin \theta_{5}-\sin \theta_{4}\right) \\
& -2\left(\theta_{5}-\theta_{4}\right) \\
C_{p 6} & =\sin \theta_{6}+\cos \theta_{6}-1
\end{aligned}
$$

Where: $\theta_{1}=0.5236, \theta_{2}=1.57, \theta_{3}=2.355, \theta_{4}=2.616$, $\theta_{5}=3.14$, and $\theta_{6}=0.785 \mathrm{rad}$.

Hence, the theoretical power coefficient $\left(C_{P}\right)$ of the proposed VAWT design is equal to $(0.44996)$ which can be considered as a promising value. 


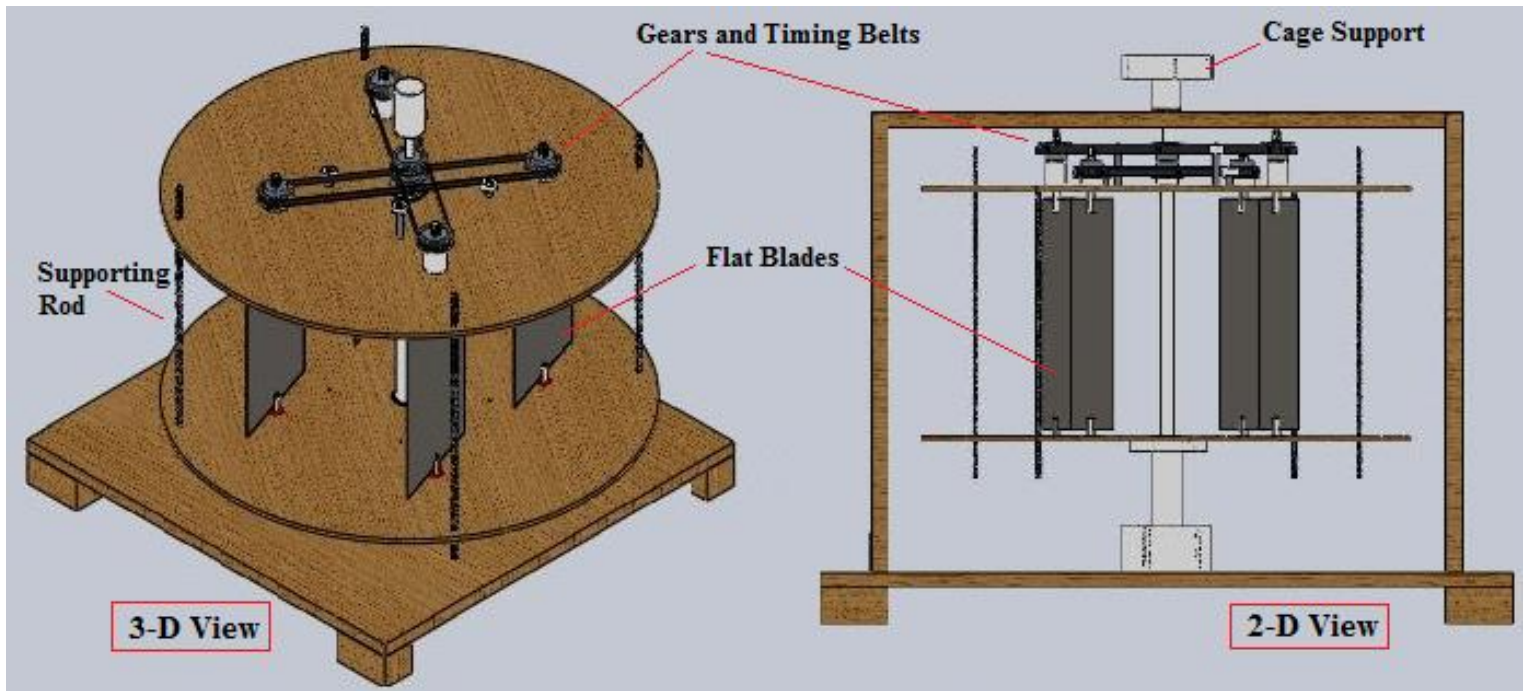

Figure 4- The 3-D and 2-D Views of the Proposed Design

\section{Prototype of the VAWT Proposed Design}

An appropriate prototype is manufactured to validate the suggested idea of improving the VAWT performance using self-oriented flat blades in addition to rotary cage. First of all, a comprehensive three dimensional model has been created for the proposed VAWT mechanical design as shown in Fig. 4, using the Solid-Works Software. In addition, a VAWT prototype of four flat blades has been built as shown in Fig. 5. Experimental testes have been performed using this prototype to validate the capability of the proposed design for achieving the VAWT blades' self-oriented motion, and to compare the experimental results of the VAWT power coefficient with theoretical ones. Suitable materials have been used for manufacturing this prototype such as; a wooden base in addition to a light plywood cylinder which is provided with a metal rear blade. This light plywood cylinder can be used as a selforiented cage. Also, a mild steel sheet of $1 \mathrm{~mm}$ thickness has been used for forming the flat turbine blades. Where the length of each turbine flat blade is equal to $300 \mathrm{~mm}$ and its width is $170 \mathrm{~mm}$. Moreover, these four metal flat blades are organized on a circle of radius equals $170 \mathrm{~mm}$, means that $(r=170 \mathrm{~mm})$. Hence, the ratio $(\alpha)$ equals to one. Also, these blades have been assembled between two suitable wooden disks of $650 \mathrm{~mm}$ diameters. Furthermore, a turbine shaft which has $30 \mathrm{~mm}$ diameter has been assembled between the two wooden disks. This turbine shaft in addition to eight short bars are fabricated from Acetal, which has shear strength equals (55 MPa) and tensile strength is equal to (61 MPa). These short bars can be used as the blades' axels. Four of these bars are fixed with the timing belt's pulleys as shown in Fig. 6.

Pilot runs of the VAWT prototype have been performed using wind stream which is generated from a wind tunnel. The used wind tunnel can generate wind stream with an approximately wind speed equals $12 \mathrm{~m} / \mathrm{sec}$ at its square outlet which has dimensions $(450 \times 450 \mathrm{~mm})$. Also, this wind tunnel body has been fabricating from a mild steel sheet of $(1 \mathrm{~mm})$ thickness. This tunnel has length equals 1500 $\mathrm{mm}$ as shown in Fig. 7.

The performed pilot runs reveal that the proposed design is capable of performing the required selforiented motions of the cage and blades. In Fig. 8, three successive positions related to the cage's rear blade of VAWT prototype are demonstrated. These three positions indicate that the rotation motion of the cage by its rear blade's effect can directly readjust the blades' surfaces to be perpendicular to the cage's rear blade, hence, VAWT blades' surfaces can be directly face the wind stream direction. Also, Fig. 9 shows four successive rotating positions of the VAWT prototype after attaining the correct orientation of the cage's outlet towards the air direction. These four positions indicate that the self-oriented motion of the turbine's flat blades can be attained, where the gears and timing belts can rotate the flat blades around their axis with the required motion. This self-oriented motion always guarantees a continuously orthogonal orientation between the affecting wind direction and the blades' surfaces. 

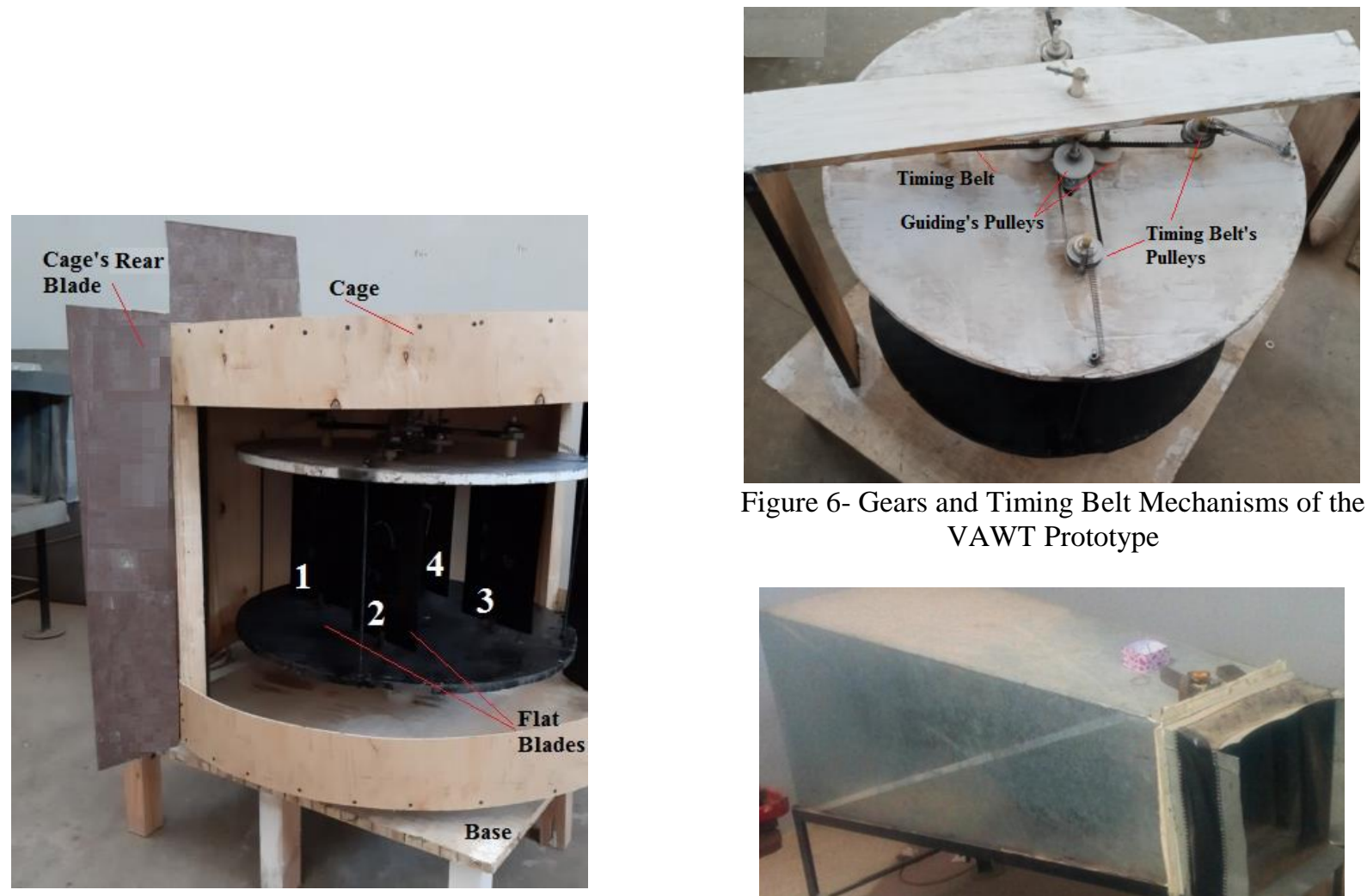

Figure 6- Gears and Timing Belt Mechanisms of the VAWT Prototype

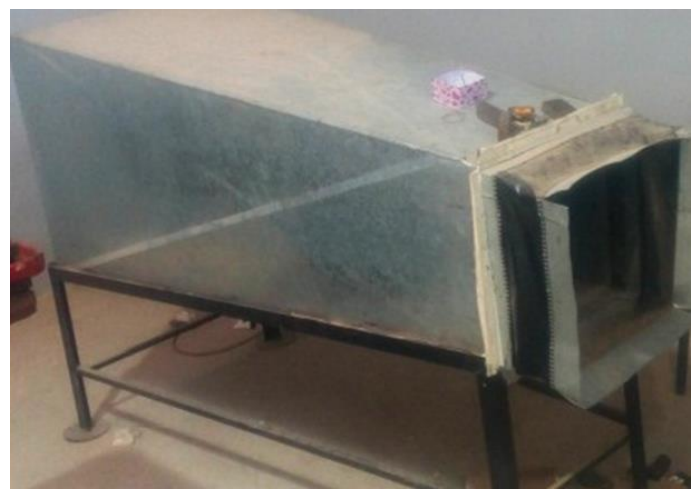

Figure 7- Wind Tunnel
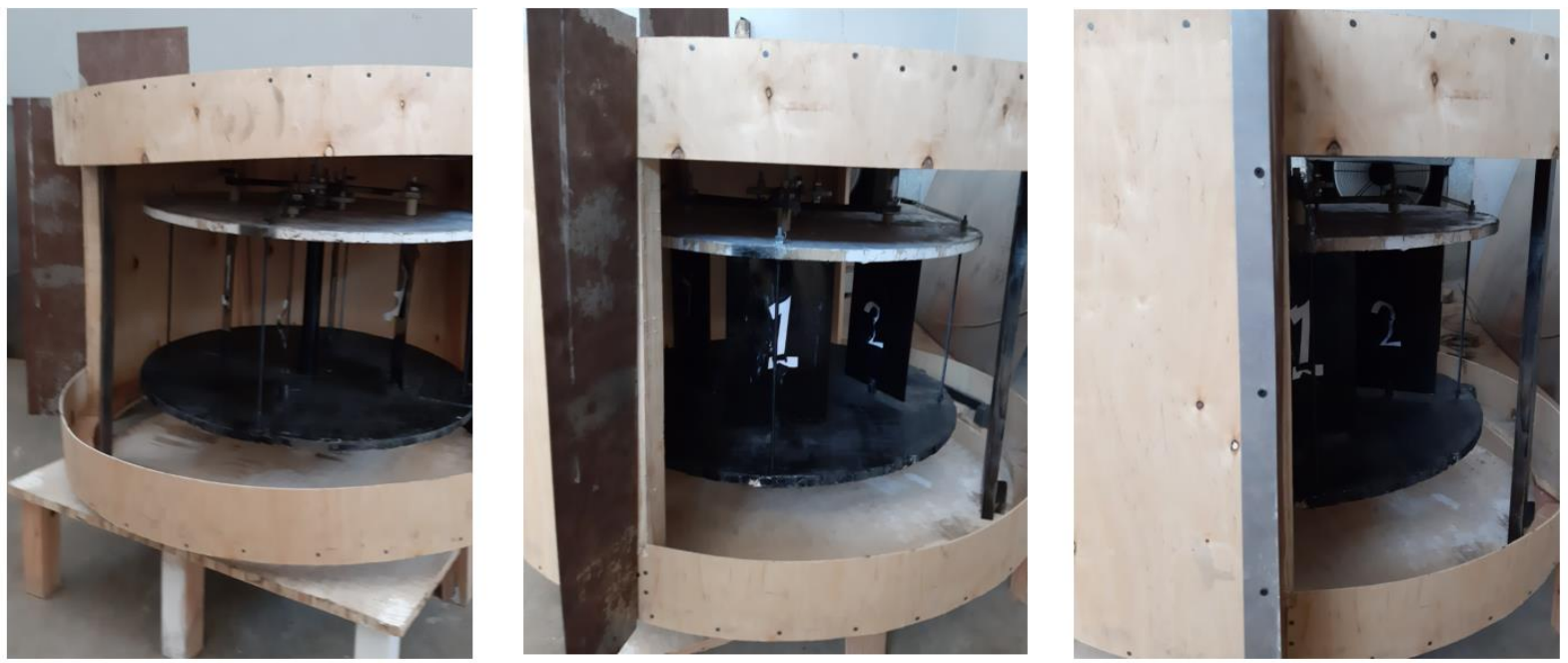

Figure 8- The Cage's Self-Oriented Motion 

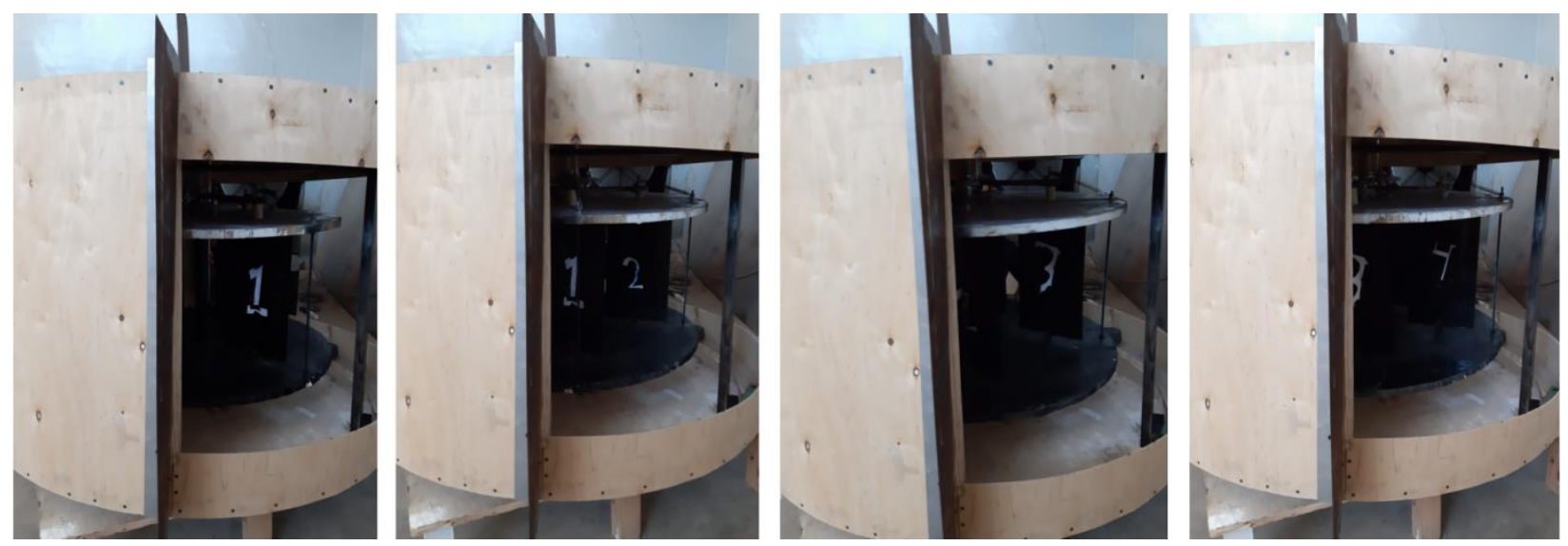

Figure 9- The Flat Blades' Self-Oriented Motion

\section{Finite Element and VAWT Prototype Natural Frequencies Analysis}

The usage of The Finite Element (FE) method can be considered as an effective tool which can be used with ANSYS software for analyzing and simulating many of mechanical systems such as the VAWT [48]. Some of the published works analyzed the wind turbines' performance using the (FE) as presented in $[49,50]$. Furthermore, a wind turbine's numerical simulation is implemented via an appropriate modal in ANSYS for studying the dynamic behavior of the turbine's structure as in [50]. The risks of the dangerous resonance circumstances and the sudden failures can be avoided by analyzing the turbine vibration behavior in addition to considering its natural frequencies as discussed in [51, 52].

ANSYS software has been used in this paper for creating a numerical modal analysis dealing with FE to get the turbine's rotor natural frequencies and the associated mode shapes. This modal analysis is based on the details of contact elements arrangements of the VAWT prototype's blades and disks. Furthermore, an active analysis can be accomplished via refining the mesh (No. of elements: 29175, Nodes: 92276 and Minimum Edge Length: 1.e-003 m) of the (FE) model to guarantee the suitable results accuracy.

\section{Results and Discussion}

The VAWT prototype's power coefficient has been evaluated through measuring the rotating angular speed of the turbine shaft and the corresponding torque during a different affecting wind speeds. Consequently, the corresponding turbine power can be evaluated by multiplying the angular speed by the corresponding measured torque. This torque can be assessed by applying an appropriate resistance coupling torque around a pulley which is mounted with the turbine rotating shaft using a rough rope. This rope can be turned around the shaft's pulley and it can be attached with weights and to digital scale (with accuracy: $\pm 0.5 \mathrm{~g}$ ). Also, the digital DT2236B laser photo tachometer (with accuracy: $\pm 0.05 \%+1$ digit), can be used for measuring the corresponding angular speed of the turbine. Thus, the corresponding power can be calculated by multiplying the resistance torque by the corresponding measured angular speed. Therefore, this evaluated power can be divided by the total input power $\left(0.5 \rho A_{s} V^{3}\right)$ for evaluating the experimental power coefficient. Hence, the experimental power coefficients can be compared with the evaluated theoretical power coefficients. Both of these theoretical and experimental power coefficients are shown in Fig. 10. These presented experimental and theoretical power coefficients have the same trend. Also, the variances between these experimental and theoretical values of power coefficients are reasonable differences related to the mechanical losses in the moving mechanical components such that the timing belts and gears.

The theoretical natural frequencies and the associated mode shapes of the VAWT prototype have been evaluated. These mode shapes are shown in Fig. 11. Furthermore, the theoretical natural frequencies of the VAWT prototype are shown in Fig. 12. These theoretical natural frequencies have high values. Thus, this VAWT can safely rotate with angular speeds lower than the values of these evaluated frequencies for avoiding the scenarios of the dangerous resonance. 


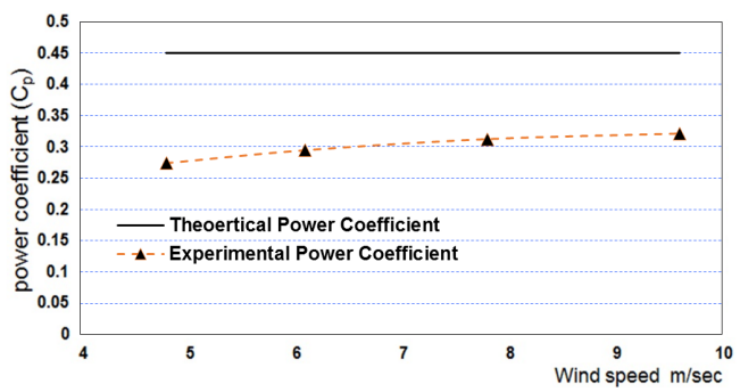

Figure 10- Theoretical and Experimental VAWT Power Coefficients
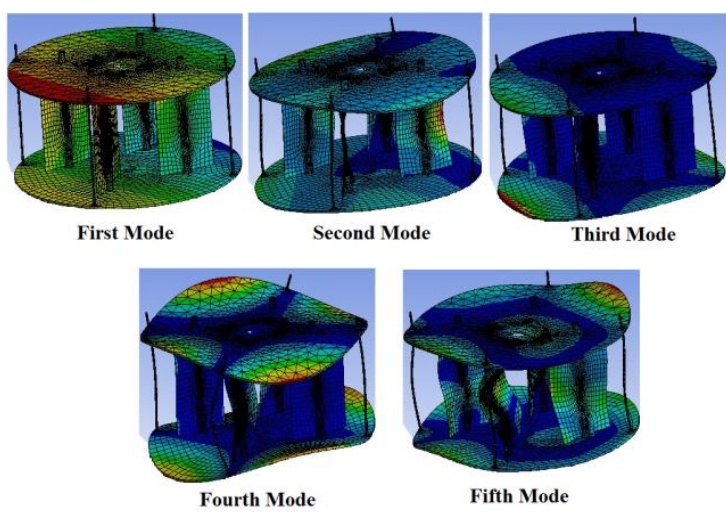

Figure 11- First Five Mode Shapes of VAWT Prototype

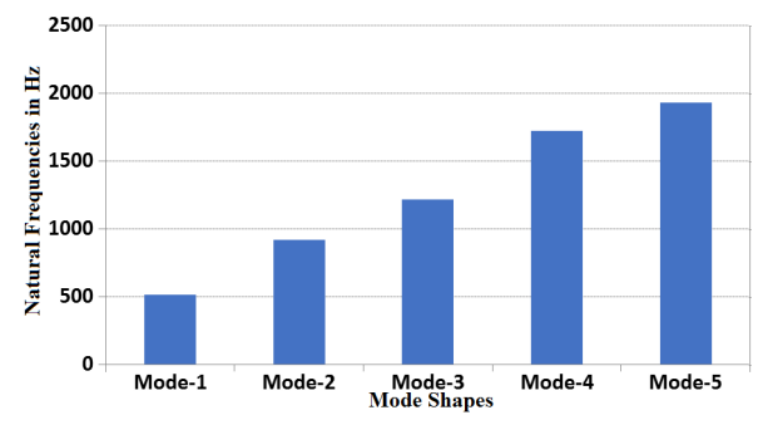

Figure 12- Theoretical Natural Frequencies

\section{Conclusions}

To assist in exploiting the full potential of the vertical wind turbine (VAWT) in harnessing wind energy, this paper introduces a VAWT that is capable of instantaneously reorient its blades to keep the orthogonality between the blade surface and the affecting wind direction, which can be maintained during the full cycle of turbine rotation. The proposed VAWT design mainly relies on a specially designed mechanical mechanism that is attached to four flat blades. The developed mechanical mechanism is basically composed a set of gears and a timing belt designed to provide the blades with the ability to be self-oriented to just continually face the hitting wind direction. The VAWT presented in this paper is particularly designed to be enclosed in self-oriented rotating hollow cylindrical container with special opening. The expected power coefficient for such a turbine has been mathematically assessed using the mathematical model developed in [46], and the obtained values are promising compared with other VAWTs. To check the validity of the proposed VAWT design, a prototype has been developed and tested using a wind tunnel. Pilot runs of the developed prototype have successfully proofed the ability of blades to effectively reorient themselves via the attached mechanism. Subsequently, the developed prototype has been employed to experimentally measure the power coefficient for the sake of comparison with theoretically assessed values. The obtained results demonstrate the same trend for the calculated values of theoretically power coefficient and experimentally ones. Besides, these results exhibit an improved performance of the proposed design as opposed to other VAWTs. Further, it should be pointed out that the flat blades utilized in the proposed design have the advantage of ease of manufacturing which can significantly reduce the production costs. The improved performance as well as the ease of manufacturing can enhance the chances of commercially producing this proposed turbine and using it in diverse applications, particularly in low investment cases. To ensure that the developed VAWT will not be subjected to the risk of resonance in its application domains, the theoretical natural frequencies have been assessed considering the first five mode shapes. The results reveal that the assessed values of the natural frequencies have high values. In addition, it has been confirmed that the developed VAWT is capable of safely rotating with no risk of resonance at considerably high speeds in different domains where the angular speeds are expected to be far lower than the values obtained for the mode shape frequencies.

\section{References}

[1] R. Inglesi-Lotz, "The impact of renewable energy consumption to economic growth: A panel data application," Energy Economics, vol. 53, pp. 58-63, 2016.

[2] S. Tiba and A. Omri, "Literature survey on the relationships between energy, environment and economic growth," Renewable and Sustainable Energy Reviews, vol. 69, pp. 1129-1146, 2017.

[3] R. Czarny, "Energy Security: Contemporary Challenges," in The Nordic Dimension of Energy Security, ed: Springer, 2020, pp. 1-22. 
[4] BP Statistical Review of World Energy, June 2020. Retrieved July $4^{\text {th }}, 2020$ from https://www.bp.com/content/dam/bp/businesssites/en/global/corporate/pdfs/energyeconomics/statistical-review/bp-stats-review2020-full-report.pdf

[5] D. Gielen, F. Boshell, D. Saygin, M. D. Bazilian, N. Wagner, and R. Gorini, "The role of renewable energy in the global energy transformation," Energy Strategy Reviews, vol. 24, pp. 38-50, 2019.

[6] C. Kahraman, İ. Kaya, and S. Cebi, "A comparative analysis for multiattribute selection among renewable energy alternatives using fuzzy axiomatic design and fuzzy analytic hierarchy process," Energy, vol. 34, pp. 16031616, 2009.

[7] B. Haddad, A. Liazid, and P. Ferreira, "A multicriteria approach to rank renewables for the Algerian electricity system," Renewable energy, vol. 107, pp. 462-472, 2017.

[8] P. Rani, A. R. Mishra, A. Mardani, F. Cavallaro, M. Alrasheedi, and A. Alrashidi, "A novel approach to extended fuzzy TOPSIS based on new divergence measures for renewable energy sources selection," Journal of Cleaner Production, vol. 257, p. 1-17, 2020.

[9] A. Maghsoodi, A. Mosavi, T. Rabczuk, and E. K. Zavadskas, "Renewable energy technology selection problem using integrated h-swaramultimoora approach," Journal of Sustainability, vol. 10, p. 1-18, 2018.

[10] A. Kumar, B. Sah, A. Singh, Y. Deng, X. He, P. Kumar, et al., "A review of multi criteria decision making (MCDM) towards sustainable renewable energy development," Renewable and Sustainable Energy Reviews, vol. 69, pp. 596-609, 2017.

[11] Y. Wang, L. Xu, and Y. A. Solangi, "Strategic renewable energy resources selection for Pakistan: Based on SWOT-Fuzzy AHP approach," Sustainable Cities and Society, vol. 52, p. 1-35, 2020.

[12] A. Adly, "Climate change and energy decision aid systems for the case of Egypt," in Climate Change and Energy Dynamics in the Middle East, ed: Springer, pp. 79-107, 2019.

[13] C. Nandi, S. Bhattacharjee, and S. Chakraborty, "Climate change and energy dynamics with solutions: a case study in Egypt," in Climate Change and Energy Dynamics in the Middle East, ed: Springer, pp. 225-257, 2019.

[14] Y. Rady, M. Rocco, M. Serag-Eldin, and E. Colombo, "Modelling for power generation sector in Developing Countries: Case of Egypt," Energy, vol. 165, pp. 198-209, 2018.
[15] A. Aliyu, B. Modu, and C. Tan, "A review of renewable energy development in Africa: A focus in South Africa, Egypt and Nigeria," Renewable and Sustainable Energy Reviews, vol. 81, pp. 2502-2518, 2018.

[16] A. Khalil, A. Mubarak, and S. Kaseb, "Road map for renewable energy research and development in Egypt," Journal of Advanced Research, vol. 1, pp. 29-38, 2010.

[17] M. Moness and A. Moustafa, "A critical review of research trends for wind energy in Egypt: recent progress and promising opportunities," International Journal of Energy Technology and Policy, vol. 15, pp. 31-70, 2019.

[18] W. Tong, Wind power generation and wind turbine design: WIT press, 2010.

[19] S. Eriksson, H. Bernhoff, and M. Leijon, "Evaluation of different turbine concepts for wind power," renewable and sustainable energy reviews, vol. 12, pp. 1419-1434, 2008.

[20] M. Johari, M. Jalil, and M. Shariff, "Comparison of horizontal axis wind turbine (HAWT) and vertical axis wind turbine (VAWT)," International Journal of Engineering and Technology, vol. 7, pp. 74-80, 2018.

[21] M. Saad and N. Asmuin, "Comparison of horizontal axis wind turbines and vertical axis wind turbines," IOSR Journal of Engineering (IOSRJEN), vol. 4, pp. 27-30, 2014.

[22] K. Pope, I. Dincer, and G. Naterer, "Energy and exergy efficiency comparison of horizontal and vertical axis wind turbines," Renewable energy, vol. 35, pp. 2102-2113, 2010.

[23] M. Bhutta, N. Hayat, A. Farooq, Z. Ali, S. Jamil, and Z. Hussain, "Vertical axis wind turbine-A review of various configurations and design techniques," Renewable and Sustainable Energy Reviews, vol. 16, pp. 1926-1939, 2012.

[24] R. Kumar, K. Raahemifar, and A. Fung, "A critical review of vertical axis wind turbines for urban applications," Renewable and Sustainable Energy Reviews, vol. 89, pp. 281-291, 2018.

[25] R. Gupta and A. Biswas, "CFD analysis of flow physics and aerodynamic performance of a combined three-bucket Savonius and threebladed Darrieus turbine," International journal of green energy, vol. 8, pp. 209-233, 2011.

[26] M. Castelli and E. Benini, "Comparison between lift and drag-driven VAWT concepts on low-wind site AEO," World Academy of Sciene, Engineering and Technology, pp. 16771682, 2011.

[27] J. Gavaldà, J. Massons, and F. Diaz, "Experimental study on a self-adapting Darrieus-Savonius wind machine," Solar \& Wind Technology, vol. 7, pp. 457-461, 1990. 
[28] A. Pallotta, D. Pietrogiacomi, and G. Romano, "HYBRI-A combined Savonius-Darrieus wind turbine: Performances and flow fields," Energy, vol. 191, p. 1-23, 2020.

[29] T. Wakui, Y. Tanzawa, T. Hashizume, and T. Nagao, "Hybrid configuration of Darrieus and Savonius rotors for stand-alone wind turbinegenerator systems," Electrical Engineering Conference in Japan, vol. 150, pp. 13-22, 2005.

[30] S. Chawla, A. Chauhan, and S. Bala, "Parametric study of hybrid Savonius-Darrieus turbine," in 2015 2nd International Conference on Recent Advances in Engineering \& Computational Sciences (RAECS), pp. 1-5, 2015.

[31] W. Wang, J. Wang, and W. Chong, "The effects of unsteady wind on the performances of a newly developed cross-axis wind turbine: A wind tunnel study," Renewable Energy, vol. 131, pp. 644-659, 2019.

[32] R. Howell, N. Qin, J. Edwards, and N. Durrani, "Wind tunnel and numerical study of a small vertical axis wind turbine," Renewable energy, vol. 35, pp. 412-422, 2010.

[33] A. Molina, T. Troyer, T. Massai, A. Vergaerde, M. Runacres, and G. Bartoli, "Effect of turbulence on the performance of VAWTs: An experimental study in two different wind tunnels," Journal of Wind Engineering and Industrial Aerodynamics, vol. 193, p. 1-12, 2019.

[34] N. Korprasertsak and T. Leephakpreeda, "Analysis and optimal design of wind boosters for Vertical Axis Wind Turbines at low wind speed," Journal of Wind Engineering and Industrial Aerodynamics, vol. 159, pp. 9-18, 2016.

[35] K. Lee, S. Tsao, C. Tzeng, and H. Lin, "Influence of the vertical wind and wind direction on the power output of a small vertical-axis wind turbine installed on the rooftop of a building," Applied Energy, vol. 209, pp. 383-391, 2018.

[36] L. Gumilar, A. Kusumawardana, M. Habibi, A. Afandi, D. Prihanto, and A. Aji, "Performance analysis of vertical wind turbine type savonius-1 based on wind speed, rotation speed, and number of blades," in 2019 International Seminar on Application for Technology of Information and Communication (iSemantic), pp. 383-388, 2019.

[37] A. Rezaeiha, I. Kalkman, and B. Blocken, "Effect of pitch angle on power performance and aerodynamics of a vertical axis wind turbine," Applied energy, vol. 197, pp. 132-150, 2017.
[38] B. Mantravadi, K. Sriram, A. Mohammad, L. Vaitla, and R. Velamati, "Effect of solidity and airfoil on the performance of vertical axis wind turbine under fluctuating wind conditions," International Journal of Green Energy, vol. 16, pp. 1329-1342, 2019.

[39] X. Sun, J. Zhu, A. Hanif, Z. Li, and G. Sun, "Effects of blade shape and its corresponding moment of inertia on self-starting and power extraction performance of the novel bowlshaped floating straight-bladed vertical axis wind turbine," Sustainable Energy Technologies and Assessments, vol. 38, p. 1-18, 2020.

[40] M. Zamani, S. Nazari, S. Moshizi, and M. Maghrebi, "Three dimensional simulation of Jshaped Darrieus vertical axis wind turbine," Energy, vol. 116, pp. 1243-1255, 2016.

[41] M. Hameed, S. Afaq, and F. Shahid, "Finite element analysis of a composite VAWT blade," Ocean Engineering, vol. 109, pp. 669-676, 2015.

[42] L. Wang, A. Kolios, T. Nishino, P. Delafin, and T. Bird, "Structural optimisation of vertical-axis wind turbine composite blades based on finite element analysis and genetic algorithm," Composite Structures, vol. 153, pp. 123-138, 2016.

[43] M. Zheng, Y. Li, H. Teng, J. Hu, Z. Tian, and Y. Zhao, "Effect of blade number on performance of drag type vertical axis wind turbine," Applied solar energy, vol. 52, pp. 315320, 2016.

[44] W. Chong, W. Muzammil, K. Wong, C. Wang, M. Gwani, Y. Chu, et al., "Cross axis wind turbine: Pushing the limit of wind turbine technology with complementary design," Applied Energy, vol. 207, pp. 78-95, 2017.

[45] N. Alom and U. Saha, "Four decades of research into the augmentation techniques of Savonius wind turbine rotor," Journal of Energy Resources Technology, vol. 140, 2018.

[46] K. Khader and O. Nada, "Using crank-crank mechanism to reorient flat blades of vertical wind turbine for improving its performance," Alexandria Engineering Journal, 2020, https://doi.org/10.1016/j.aej.2020.07.020

[47] C. Jian, J. Kumbernuss, Z. Linhua, L. Lin, and Y. Hongxing, "Influence of phase-shift and overlap ratio on savonius wind turbine's performance", Solar Energy Engineering, ASME J., vol. 134, pp. 161-169, 2012. 
[48] H. Lee, "Finite Element simulations with ANSYS 18, theories, applications, case studies", SDC Publications, p.417-464, 2018. https://books.google.com.eg/books?id=LdNT DwAAQBAJ\&printsec $=$ frontcover\&hl=ar\&so urce $=$ gbs_ge_summary_r\&cad $=0 \# v=$ onepage $\& q \& \mathrm{f}=$ false

[49] Y. Ishida, T. Inoue, and K. Nakamura, "Vibration of a wind turbine blade: theoretical analysis and experimental using a single rigid blade model", Environment and Engineering J., vol. 4, no. 2, pp. 443-454, 2009.

[50] M. Shzu, M. Morais, Z. Del-Prado, and S. Avila, "Finite element analysis of a wind turbine tower with a pendulum tuned mass damper", Proceedings of the XVII International Symposium on Dynamic Problems of Mechanics, Natal, Brazil, pp.1-8, Feb. 2015.

[51] G Taware, S. Mankar, V. Ghagare, G. Bharambe, and S. Kale, "Vibration analysis of a small wind turbine blade", International Journal of Engineering and Technology (IJET), vol. 8, no. 5, pp.2121-2126, 2016.

[52] M. Alonso-Martinez, J. Adam, F. AlvarezRabanal, and J. Díaz, "Wind turbine tower collapse due to flange failure: FEM and DOE analyses", Engineering Failure Analysis J., vol. 104, pp.932-949, 2019. 